\title{
Job Stressors and the Pursuit of Sport Activities: A Day-Level Perspective
}

\author{
Sabine Sonnentag and Stefanie Jelden \\ University of Konstanz, Konstanz, Germany
}

\begin{abstract}
This article addresses the relation between day-specific experiences of job stressors and the pursuit of off-job activities. Following the limited-resources model of self-regulation, the authors proposed that job stressors and long working hours are negatively related to pursuit of sport activities after work because, after stressful days, employees have no resources left for initiating and persisting in effortful behaviors such as sport. Routines for off-job activities were hypothesized to be positively related to the pursuit of sport activities after work. Seventy-eight police employees completed a daily survey over 5 working days and indicated that they perceive sport to be highly useful for recovery. Random coefficient modeling showed that job stressors (particularly situational constraints) encountered on a specific day were negatively related to self-regulatory resources and to the amount of time spent on sport activities after work, whereas the relation with low-effort activities was positive. Thus, after a stressful day when an effective recovery activity such as sport is highly needed, persons tend to engage less in such an activity.
\end{abstract}

Stressors encountered at work affect people's health and life outside work. This has been shown both with respect to longer term processes observed over the course of months or years (e.g., Demerouti, Bakker, \& Bulters, 2004; Garst, Frese, \& Molenaar, 2000; Jannson $\&$ Linton, 2006) and with respect to shorter-term processes within single days (Elfering et al., 2005; Zohar, 1999). Most of this day-level research has focused on mood-related effects of experiences at work (Ilies, Schwind, \& Heller, 2007). Little is known about how day-specific job stressors influence health-related behaviors that have long-term health implications. In this article, we focus on one specific type of health-related behavior, namely sport activities.

There is ample evidence that sport and related activities have a positive effect on individual health and well-being (Petruzzello, Landers, Hatfield, Kubitz, \& Salazar, 1991; Puetz, O’Connor, \& Dishman, 2006). In addition, it seems that people are aware of the positive effects of sport on well-being (Thayer, Newman, \& McClain, 1994). However, compared with other off-job activities, people spend relatively little time on exercise and sport (Dubbert, 2002).

Sabine Sonnentag and Stefanie Jelden, Department of Psychology, University of Konstanz, Konstanz, Germany.

Correspondence concerning this article should be addressed to Sabine Sonnentag, University of Konstanz, Department of Psychology, Postbox D42, D-78457 Konstanz, Germany. E-mail: sabine.sonnentag@uni-konstanz.de
Cross-sectional studies suggest that persons experiencing life stress or working in highly stressful jobs have difficulties engaging in sport behavior and acting on sport-related goals ( $\mathrm{Ng} \&$ Jeffery, 2003; Payne, Jones, \& Harris, 2002; however, cf. Hellerstadt \& Jeffery, 1997). Studies that looked at the relation between stress and physical activities such as sport within persons have suggested that people engage less in these activities during stressful weeks than during less stressful weeks (Oaten \& Cheng, 2005; Stetson, Rahn, Dubbert, Wilner, \& Mercury, 1997; however, cf. Steptoe, Lipsey, \& Wardle, 1998). To the best of our knowledge, there is no study that has addressed variations of job stressors at the day level and associated variations in sport activities. A day-level perspective, however, is necessary to better understand how job stressors affect an individual's functioning on a daily basis and how they may interfere with the regularity of sport behavior.

Moreover, very little is known about why day-level job stressors should be related to a low engagement in sport activities. In this article, we draw on the limitedresources view of self-regulation (Muraven \& Baumeister, 2000). We argue that job stressors deplete selfregulatory resources (i.e., energy necessary to engage in behaviors that require self-control; cf. Gaillot et al., 2007) and that depletion of self-regulatory resources accounts for the failure to pursue sport activities.

The purpose of this study is first to examine day-level job stressors as predictors of engagement in sport and 
other off-job activities. Second, we test depletion of self-regulatory resources as the mediating mechanism. Third, as additional research questions, we examine whether routines for off-job activities and number of hours worked are related to time spent on off-job activities. We adopt a day-level perspective for several reasons: First, job stressors and time spent on off-job activities fluctuate largely from day to day (Ilies et al., 2007; van Hooff, Geurts, Kompier, \& Taris, 2006). Second, the depletion of self-regulatory resources exerts its effects on individual behavior most obviously within single days (cf. Schmeichel \& Baumeister, 2004). It is necessary to analyze the relation between job stressors, resources for self-regulation, and activities at the day level because between-person analyses and analyses within longer time frames (e.g., week level) obscure the processes operating within individuals in their daily lives (cf. Jones, O'Connor, Conner, McMillan, \& Ferguson, 2007). Figure 1 shows our conceptual model as developed in the subsequent sections.

\section{Job Stressors}

Job stressors are conditions and events at work that evoke strain (Kahn \& Byosiere, 1992). Typical job stressors are role stressors (e.g., role ambiguity), workload (i.e., time pressure), and situational constraints (Jex, 1998). Role ambiguity refers to vague work requirements resulting in uncertainty about how to accomplish work tasks (Frese \& Zapf, 1994). Time pres- sure refers to a situation in which a high amount of work must be completed in little time (Major, Klein, \& Ehrhart, 2002). Situational constraints refer to obstacles in the work situation that hinder task accomplishment (e.g., breakdown of technical equipment or faulty material; cf. Peters, Chassie, Lindholm, O'Connor, \& Kline, 1982). In the daily work process, job stressors make task completion processes more difficult and effortful (Frese \& Zapf, 1994; Meijman \& Mulder, 1998). When confronted with job stressors, individuals must work harder, find ways to deal with hassles or unforeseen events, and have to clarify ambiguous requirements. Exerting this extra effort requires self-regulation and consumes resources (Hockey, 1997; Zohar, Tzischinski, \& Epstein, 2003).

To stay healthy and to perform well in the long run, individuals need to recover after work, particularly after stressful days (Meijman \& Mulder, 1998). Recovery occurs when an individual's functioning returns to its prestressor level and when strain caused by the stressors is reduced (Craig \& Cooper, 1992). Empirical research has shown that job stressors are related to individuals' subjective need for recovery (De Croon, Sluiter, Blonk, Broersen, \& FringsDresen, 2004; Sonnentag \& Zijlstra, 2006). Thus, after having faced a high level of stressors, individuals feel that recovery is needed. After such a stressful day when the need for recovery is high, it is necessary that individuals pursue activities that help to achieve recovery. Compared with other types of

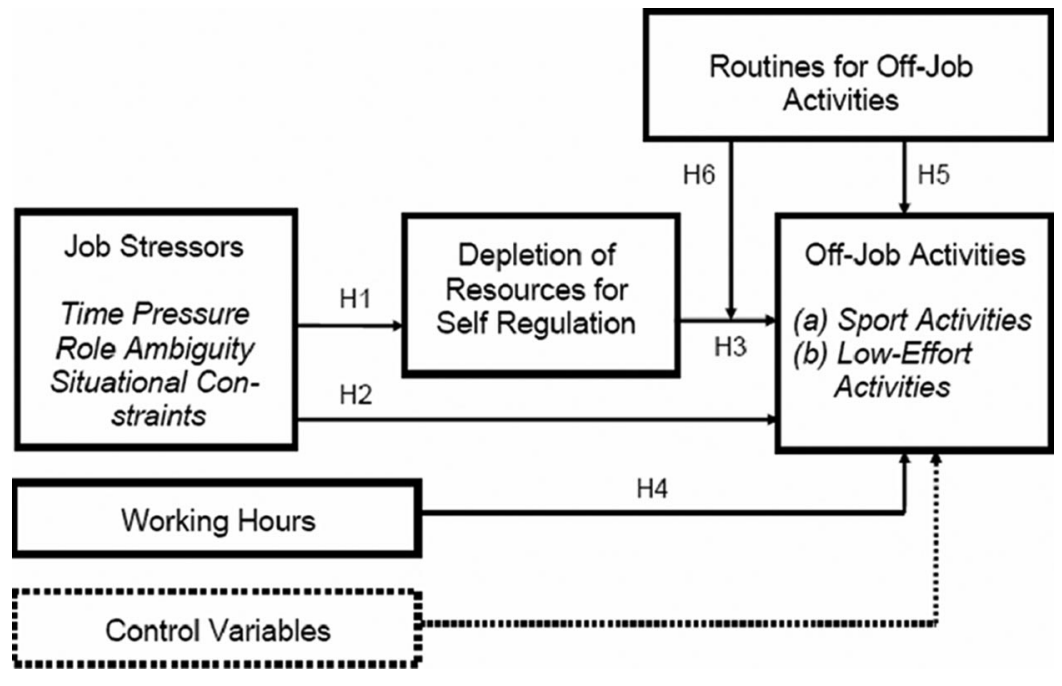

Figure 1. Conceptual model. $\mathrm{H}=$ hypothesis. 
activities, sport has been shown to be particularly beneficial for recovery (Sonnentag, 2001; Sonnentag $\&$ Natter, 2004). Similarly, sport and related activities have been identified as a powerful mood regulation strategy (Larsen \& Prizmic, 2004; Thayer, 1987). Therefore, because the experience of job stressors is associated with mood impairment (Fuller et al., 2003; Zohar et al., 2003), one would assume that, after stressful days, people would want to engage in sport activities that promote recovery and improve mood. However, many people's everyday experience and the limited-resources model of self-regulation (Muraven \& Baumeister, 2000) suggest that this is often not the case.

\section{Self-Regulation as a Limited Resource}

Muraven and Baumeister (2000) have argued that self-regulation is a limited, depletable, and domainindependent resource. Self-regulation largely overlaps with the psychological processes involved in selfcontrol (cf., Gaillot et al., 2007) and refers to processes of "the self acting on itself to alter its own processes" (Schmeichel \& Baumeister, 2004, p. 86) such as thoughts, feelings, and behavior. Self-regulation has been described as "the capacity to override one's impulses and automatic or habitual responses" (Gaillot \& Baumeister, 2007, p. 303). This conceptualization of self-regulation as a limited resource implies that, after self-regulation has been required, subsequent selfregulation will suffer, not only within one domain but also across domains. For example, after a high degree of self-regulation was needed at the workplace, not only subsequent self-regulation at work but also selfregulation during leisure time will be impeded. In other words, after a confrontation with job stressors that require self-regulation, it will be more difficult to exert self-regulation in subsequent off-job activities. For instance, imagine a spokesperson of a police department who faces a breakdown of the computer system while dealing with urgent requests from the public. In such a situation, this person needs a high degree of selfregulation, not to get angry but to stay calm and focused. When the day at work is over, however, this person's self-regulatory resources will be depleted, and it will be difficult for him or her to keep up selfregulation when confronted with self-regulatory demands at home.

Empirical research supports this view of selfregulation as a limited resource. Compared with control groups, study participants who were required to exert a high degree of self-regulation during the first part of an experiment gave up more quickly during a second task and showed more passive behavior (Baumeister, Bratslavsky, Muraven, \& Tice, 1998).

\section{Self-Regulation, Sport Activities, and Low-Effort Activities}

Sport activities typically require a high degree of self-regulation, with respect to both the initiation of sport activities (i.e., getting started) and the pursuit of sport over longer periods of time (i.e., resisting the temptation to give up when fatigue arises). Thus, when self-regulation is impaired, it is more difficult for a person to initiate as well as continue sport activities after having started them. A major reason for this process is that sport requires high levels of effort (Tenenbaum \& Hutchinson, 2007). After a day at work, people have a "natural" tendency to avoid additional effort expenditure. Self-regulation is required to override this tendency to refrain from effort expenditure. Also, self-regulation is crucial with respect to physiological processes that provide energy for the physical activity itself (Gaillot et al., 2007). In contrast to sport, many other off-job activities require less self-regulation. Even when resources are depleted, a person can easily start and uphold low-effort activities such as watching television, browsing through a newspaper, chatting with his or her spouse, or just sitting on the sofa. Of course, sport and low-effort activities are not the only activities persons engage in during off-job time, and sport is not the only type of activity that requires self-regulation. However, here we focus on sport and low-effort activities because we assume that they are largely distinct with respect to the resources they require for effort investment and self-regulation, and because sport is highly important with respect to health outcomes.

Because dealing with job stressors requires selfregulation, a person's resources tend to be depleted after a highly stressful working day. As a consequence, this person will have fewer resources available when returning home from work and will be less able to exert self-regulation. Therefore, it will be less likely that this person starts off-job time activities that require a high degree of self-regulation. In addition, he or she will more easily follow the temptation to give up an effortful activity (Baumeister et al., 1998). Moreover, people may feel that some rest is needed when their self-regulatory resources are depleted (Schmeichel \& Baumeister, 2004). Therefore, one can assume that, when self-regulatory resources are depleted, people may not only refrain 
from activities that require self-regulation but may also deliberately pursue activities that put little emphasis on self-regulation. In terms of more specific activity categories, one can assume that people will engage less in sport activities after having been exposed to stressful situations requiring self-regulation.

It is important to note that, after a stressful day at work, people will not just reduce their engagement in sport activities, which, in turn, would cause more time to be available for other types of activities (e.g., social activities such as meeting with friends; attending cultural events). We assume that, after a stressful day at work, people will engage more in low-effort activities that require little self-regulation. Specifically, we propose the following:

Hypothesis 1: Exposure to job stressors is negatively related to resources available for selfregulation.

Hypothesis 2A: Exposure to job stressors is negatively related to the amount of time spent on sport activities after work.

Hypothesis 2B: Exposure to job stressors is positively related to the amount of time spent on low-effort activities after work.

Hypothesis 3A: Resources for self-regulation mediate the negative relation between job stressors and amount of time spent on sport activities after work.

Hypothesis 3B: Resources for self-regulation mediate the positive relation between job stressors and amount of time spent on low-effort activities after work.

\section{Working Hours}

Not only self-regulatory resources but also other resources, particularly time resources, are relevant for engaging in off-job activities. Time resources for responsibilities and activities outside work largely depend on the number of work hours (e.g., Major et al., 2002). When working long hours, a person has less time available for off-job activities. Betweenperson analyses have shown that long work hours interfere with time spent on sport (Nomaguchi \& Bianchi, 2004). We assume that a similar pattern of relations also holds at the day level because long working hours on a specific day limit the amount of time that can be devoted to other activities. More- over, long working hours should also limit the amount of time spent on low-effort activities.

Hypothesis 4A: Number of hours worked on a specific day is negatively related to the amount of time spent on sport activities after work.

Hypothesis $4 B$ : Number of hours worked on a specific day is negatively related to the amount of time spent on low-effort activities after work.

\section{Routines for Off-Job Activities}

We suggest that routines for off-job activities are beneficial for initiating effortful activities. Generally, a routine or a habit is a behavioral tendency to repeat responses in a stable context (Ouellette \& Wood, 1998). Having routines for off-job activities refers to the tendency to regularly pursue specific off-job activities at specific times or in specific contexts. In other words, a person who has developed routines for off-job activities has plans available about when to engage in which kind of off-job activity (e.g., engaging in sport every Wednesday or meeting with friends every Friday). The initiation of routine behavior does not primarily depend on deliberation and active choices but on automatic processes (Aarts \& Dijksterhuis, 2000; Wood, Quinn, \& Kashy, 2002). Therefore, routines are associated with selfregulatory benefits. In terms of the limited-resources model of self-regulation, the initiation of routine behavior requires less self-regulatory resources. As the initiation of routine behavior requires less selfregulatory resources than the initiation of behavior by active choice (Baumeister et al., 1998), more selfregulatory resources remain available that can be used for persisting in effortful behavior. Thus, routines should help not only to initiate behavior that requires self-regulation but also to persist in such behavior after having started it. We propose that, when a person has developed routines for off-job activities (i.e., routines used to pursue specific activities at specific, preplanned times), he or she will need less self-regulation to start the respective activities. For example, if someone regularly plays soccer Wednesday evening or goes running every Thursday evening, this person will be more likely to play soccer or run on the respective day than a person who deliberately decides every evening whether to pursue sport. Routines for off-job activities will also help the person to uphold the sport activity on the specific day. 
Hypothesis 5: Routines for off-job activities are positively related to the amount of time spent on sport activities during the evening.

We propose that routines for off-job activities are particularly helpful when self-regulatory resources tend to be depleted. Routines for off-job activities can compensate for a lack of selfregulatory capacity. For example, to start and persist in sport activities, people can rely on their pre-established routines rather than on (suboptimal) self-regulation. Routines for off-job activities will also matter with respect to low-effort activities. Routines for off-job activities have the potential to attenuate the association between selfregulatory resources and the pursuit of low-effort activities. A person with highly routinized off-job activities will be less inclined to engage in loweffort activities when self-regulatory resources are depleted because the routine will help to initiate and to persist in other activities.

Hypothesis 6A: Routines for off-job activities attenuate the negative relation between resources for self-regulation and time spent on sport activities.

Hypothesis 6B: Routines for off-job activities attenuate the positive relation between resources for self-regulation and time spent on low-effort activities.

\section{Perceived Recovery Effects of Sport and Low-Effort Activities}

We have proposed that, after having faced a high degree of job stressors, individuals will spend less time on sport and more time on low-effort activities. An empirical finding that supports these hypotheses will not be particularly interesting if individuals perceive low-effort activities as more effective for recovery than sport activities. However, if sport activities are perceived as more powerful with respect to recovery than low-effort activities, low levels of engagement in sport activities will be more noteworthy. To decide whether a reduced engagement in sport activities after a stressful day just reflects a low preference for sport activities, it is necessary to examine how persons experience and think about sport and low-effort activities. Therefore, we compared the recovery effect that people attribute to sport and low-effort activities. Note that the core point here is not the actual effect of various types of activities but the participants' representations of the respective activities' effects.

\section{Method}

\section{Sample}

We conducted our study with police employees because police jobs are particularly stressful and largely interfere with life outside work (Roberts \& Levenson, 2001). We collected data in four police organizations in Germany. First, we approached the directors of the organizations and informed them about the study. Subsequently, we distributed survey packages to 120 police employees. Survey packages included a questionnaire, daily survey material, and a letter describing the study and stressing voluntary participation. Eighty-three completed survey packages were returned. Because of missing data in core study variables, the final sample size was reduced to 78 (response rate: $65.0 \%$ ).

Among all participants, $63.8 \%$ worked in the area of criminal investigation $(31.3 \%$ at the level of local authorities and $32.5 \%$ at the provincial level), and $26.1 \%$ held other jobs within the police. In terms of positions, $32.5 \%$ of all participants had jobs as constables including duties on the streets, $6.0 \%$ were detective superintendents, $44.6 \%$ were detective chief superintendents with a high proportion of administrative tasks, and the remaining $16.9 \%$ had higher level administrative and management positions. Overall, $41.0 \%$ of our participants worked in a supervisory position. Mean age of study participants was 43.8 years $(S D=7.7)$. The majority of the sample was male $(85.9 \%)$. Mean professional experience was 24.7 years $(S D=8.1)$. Average number of hours worked overtime per week was $5.9(S D=5.0)$. Most participants lived with a partner $(84.6 \%)$ and had children $(79.5 \%)$.

\section{Procedure}

We used a questionnaire and a daily survey for data collection. The questionnaire assessed routines for off-job activities, demographic variables, and the assumed recovery effect of sport and low-effort activities. After having responded to the questionnaire, participants were asked to complete the daily survey over a period of 5 working days at two measurement occasions per day: On returning home from work, participants reported day-specific job stressors, number of hours worked on the specific day, resources for self-regulation, and fatigue. Before going to bed, 
participants provided data on the amount of time spent on sport and low-effort activities during the specific evening and on the experienced recovery effect of sport and low-effort activities.

\section{Measures}

All measures (except for resources for selfregulation, fatigue, demographic variables, and time reports) were assessed with 5-point rating scales.

Job stressors. As research has shown that organizational stressors (e.g., time pressure) are more prevalent in police jobs than are operational stressors (e.g., arresting a violent person; Kop, Euwema, \& Schaufeli, 1999), we focused on organizational stressors in our study. We assessed day-specific time pressure, role ambiguity, and situational constraints with short scales adopted from job stressor measures developed by Semmer (1984) and Zapf (1993). These measures are widely used in German-speaking countries and show satisfactory to good validity (Semmer, Zapf, \& Dunckel, 1999). For economy reasons, we shortened the original scales and assessed time pressure with three items (e.g., "Today, I was under time pressure at my work"), role ambiguity with two items (e.g., "I had to make decisions at work, without having enough information"), and situational constraints with three items (e.g., "Today, I had to work with materials and information that were incomplete and outdated"). Cronbach's alphas computed separately for the 5 days ranged between 0.87 and 0.92 $(M=0.89)$ for time pressure, between 0.64 and 0.77 $(M=0.70)$ for role ambiguity, and between 0.66 and $0.80(M=0.70)$ for situational constraints.

Resources for self-regulation and fatigue. Following recent advancements in self-regulation research emphasizing energy as the core component of self-regulatory resources (Gaillot et al., 2007), we measured resources for self regulation by assessing a person's energy level after work with four vigor items (e.g., vigorous, lively) from the Profile of Mood States (McNair, Lorr, \& Droppelman, 1971) on a 7-point rating scale. Cronbach's alphas ranged between 0.88 and $0.94(M=0.90)$. We assessed fatigue after work as a potential alternative explanatory mechanism for the assumed relation between job stressors and time spent on sport and low-effort activities. We included fatigue as an additional potential mediator variable to test whether engagement in sport activities decreases just because fatigue is high after a stressful day at work. We measured fatigue with four items (e.g., fatigued, tired) from the Profile of Mood States (McNair et al., 1991) on a 7-point rating scale. Cronbach's alphas ranged between 0.88 and $0.94(M=0.91)$. To examine whether resources for self-regulation and fatigue are distinct constructs, we conducted a confirmatory factor analysis using scores centered at the person mean (cf. Bolger, Davis, \& Rafaeli, 2003). A two-factor model with selfregulation items loading on a self-regulation factor and fatigue items loading on a fatigue factor showed a satisfactory fit $\left(\chi^{2}[19]=45.43\right.$; nonnormed fit index $=0.99$, comparative fit index $=0.99$, root mean square error of approximation $=0.059$ ) and fitted the data better than a one-factor model with all items loading on one single factor, $\Delta \chi^{2}(1)=261.28$, $p<.001$.

Time spent on sport and low-effort activities. To measure the amount of time spent on off-job activities, we followed the procedure used by Sonnentag (2001). In the daily survey, we provided short descriptions of various activity categories: (a) sport activities (e.g., running, cycling, swimming), (b) loweffort activities (e.g., watching television, reading a newspaper, doing nothing), (c) social activities, (d) household activities, (e) work-related activities, and (f) other activities. We included this broad range of activities to avoid demand characteristics of the study. For all activity categories, participants reported whether they had pursued the activity and how much time they had spent on the activities.

Hours worked. We assessed number of hours worked on the specific day with one single item.

Routines for off-job activities. We measured routines for off-job activities with three questionnaire items. These items referred to the degree to which participants have developed routines about how to spend their off-job time (e.g., "Usually, I perform specific off-job activities on specific days"). Cronbach's $\alpha$ was 0.85 .

Assumed and experienced recovery effects. The assumed recovery effect of sport and low-effort activities was measured with two single-item measures in the questionnaire: "Physical sport activities (e.g., running, cycling) have a recovering effect for me" and "Low-effort activities (e.g., watching TV, reading, listening to music) have a recovering effect for me." The experienced recovery effect of sport and low-effort activities was assessed each day with the daily survey. Specifically, when participants reported that they had performed a specific activity (e.g., sport activity, low-effort activity), they were asked to respond to three items assessing experienced recovery (e.g., "After having performed these activities, I felt more recovered"). Cronbach's alphas of experienced recovery on the 5 days ranged between 0.57 and 0.82 
$(M=0.73)$ for sport activities and between 0.81 and $0.87(M=0.85)$ for low-effort activities.

Control variables. We assessed gender, age, and number of children with single items.

\section{Results}

\section{Descriptive Results}

Table 1 shows means, standard deviations, and zero-order correlations between study variables. To analyze whether participants' experiences and activities differ from day to day and whether it is sensible to follow a multilevel approach, we examined withinperson and between-persons variation of the daylevel measures across the 5 days. Table 2 displays results from one-way analysis of variance (ANOVA) with random effects (null models). The percentages of variance attributable to within-person variability ranged between $47.3 \%$ and $83.1 \%$. These analyses demonstrating substantial within-person variation suggest analyzing data at the day level using a multilevel approach.

\section{Test of Hypotheses}

We tested our hypotheses with multilevel models using random coefficient modeling (Bryk \& Raudenbush, 1992). We centered day-level predictor variables (e.g., job stressors) around the respective person mean and person-level predictor variables (e.g., routines for off-job activities, demographic variables) around the grand mean.

To test Hypothesis 1, which predicted that job stressors are negatively related to resources for selfregulation, we compared three nested multilevel models, starting with a null model, with the intercept as the only predictor (see Table 3). Model 1 that included demographic variables as control variables did not result in an improved fit compared with the null model (difference of $-2^{*} \log =1.007$, $d f=3$, $n s$ ). Model 2, in which we entered the job stressors (time pressure, role ambiguity, situational constraints) and work hours, resulted in a significantly better fit than Model 1 (difference of $-2 * \log =$ $21.350, d f=4, p<.001)$. Situational constraints and work hours were negatively related to resources for self-regulation indicating that persons who experienced a high degree of situational constraints during their working day and who had worked long hours reported lower levels of resources for self-regulation after work. Time pressure and role ambiguity were not related to resources for self-regulation. Hypoth- esis 1 was supported for situational constraints but not for the other two job stressors.

We had hypothesized that high levels of job stressors are negatively related to the amount of time spent on sport activities (Hypothesis 2A) and that resources for self-regulation mediate this relation (Hypothesis 3A). Moreover, our hypotheses proposed that the number of hours worked is negatively related (Hypothesis 4A) and routines for off-job activities are positively related (Hypothesis 5) to the amount of time spent on sport activities. To test these hypotheses, we compared a set of nested models, with time spent on sport activities as the dependent variable. As shown in Table 4, Model 1, which included demographic variables as control variables showed no significant improvement over the null model (difference of $-2^{*} \log =7.540, d f=3, p=$ .0565). Model 2, which included job stressors, hours worked, and routines for off-job activities, fitted the data better than Model 1 (difference of $-2 * \log =$ 12.133, $d f=5, p<.05)$. Situational constraints showed a negative relation with the amount of time spent on sport activities. Hours worked showed no significant association with time spent on sport activities. Routines were positively related to the amount of time spent on sport activities.

To test for the mediation effect (cf. Baron \& Kenny, 1986), ${ }^{1}$ we entered resources for selfregulation in Model 3. In this model, the estimate of situational constraints became nonsignificant, whereas resources for self-regulation were a significant predictor of time spent on sport activities. This finding suggests that a reduced level of resources for self-regulation mediates the negative

\footnotetext{
${ }^{1}$ Baron and Kenny (1986) specified additional requirements for establishing mediation: First, the independent variable (e.g., in the present study, job stressors) must be related to the dependent variable (e.g., in the present study, time spent on sport activities). This condition was met for situational constraints (see Table 4). Second, the independent variable (e.g., in the present study, job stressors) must be related to the mediator variable (e.g., in the present study, resources for self regulation). Again, this condition was met for situational constraints (see Table 3). Third, the mediator variable must be related to the dependent variable. We examined this condition in additional multilevel model with gender, age, number of children, and routines for off-job activities as control variables, resources for self-regulation as the predictor variable, and time spent on sport activities as the dependent variable. In this model, the estimate of resources for self-regulation was significant $(\gamma=0.112$, $S E=0.043, t=2.605, p<.05)$, indicating that resources for self-regulation after work were positively related to the amount of time spent on sport activities during the evening.
} 


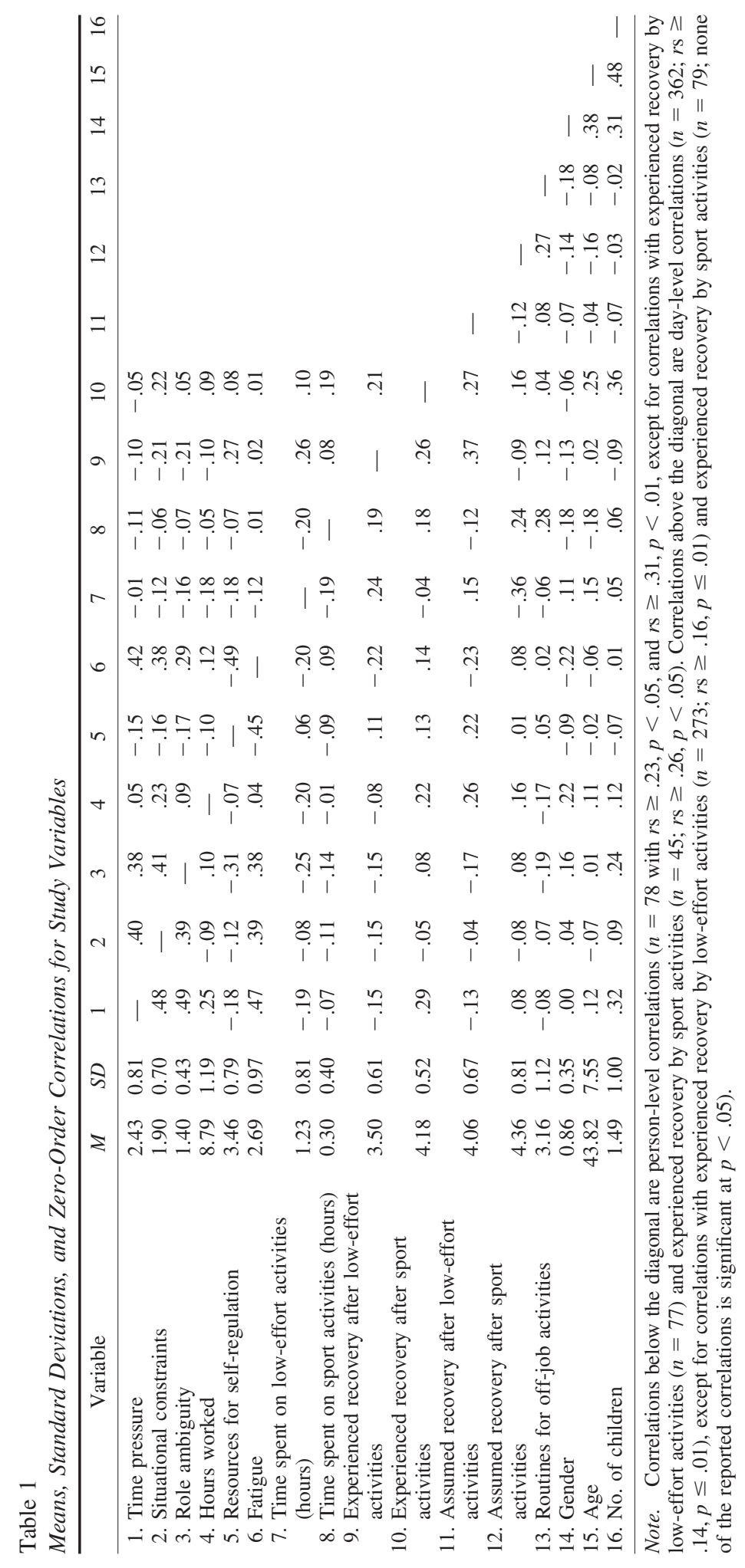


Table 2

Variance Components of Null Models for Day-Level Variables

\begin{tabular}{lccc}
\hline \multicolumn{1}{c}{ Variable } & $\begin{array}{c}\text { Day-level } \\
\text { variance }\end{array}$ & $\begin{array}{c}\text { Person-level } \\
\text { variance }\end{array}$ & $\begin{array}{r}\text { \% variability } \\
\text { within person }\end{array}$ \\
\hline Time pressure & 0.688 & 0.110 & 62.6 \\
Role ambiguity & 0.222 & 0.089 & 71.3 \\
Situational constraints & 0.335 & 0.300 & 52.8 \\
Hours worked & 2.551 & 0.828 & 75.5 \\
Resources for self-regulation & 0.731 & 0.449 & 61.9 \\
Fatigue & 0.713 & 0.795 & 47.3 \\
Sport activities & 0.404 & 0.082 & 83.1 \\
Low-effort activities & 0.890 & 0.459 & 65.9 \\
\hline
\end{tabular}

relation between situational constraints and time spent on sport activities. To test mediation more directly, we used the Sobel test and followed the procedure described by MacKinnon and Dwyer (1993) in its adaptation for multilevel data sets (Krull \& MacKinnon, 2001). Analysis resulted in an estimate of 0.022477 and a standard error of 0.00908 . The resulting $z$ statistic was significant $(z=2.474, p<.05)$, indicating that resources for self-regulation mediate the relation between situational constraints and time spent on sport activities.

In Hypothesis 6A, we hypothesized that routines for off-job activities attenuate the relation between resources for self-regulation and time spent on sport activities. We tested this hypothesis by entering the interaction term between resources for self-regulation and routines for off-job activities in Model 4. Analyses showed no improvement of model fit (difference of $\left.-2^{*} \log =1.213, d f=1, n s\right)$. Taken together, analyses provided partial support for Hypotheses 2A and $3 \mathrm{~A}$ and full support for Hypothesis 5. Hypotheses $4 \mathrm{~A}$ and $6 \mathrm{~A}$ were not supported.

We had predicted that high levels of job stressors are positively related to the amount of time spent on low-effort activities (Hypothesis 2B) and that resources for self-regulation mediate this relation ( $\mathrm{Hy}$ pothesis 3b). In addition, hours worked should be negatively related to the amount of time spent on low-effort activities (Hypothesis 4B). Again, we tested a set of nested models, now with time spent on low-effort activities as the dependent variable (see Table 5). Model 1, which included demographic

Table 3

Multilevel Estimates for Models Predicting Resources for Self-Regulation From Day-Specific Job Stressors

\begin{tabular}{|c|c|c|c|c|c|c|}
\hline \multirow[b]{2}{*}{ Variable } & \multicolumn{3}{|c|}{ Model 1} & \multicolumn{3}{|c|}{ Model 2} \\
\hline & Estimate & $S E$ & $t$ & Estimate & $S E$ & $t$ \\
\hline Intercept & 0.001 & 0.088 & 0.011 & -0.011 & 0.089 & -0.124 \\
\hline Gender & -0.175 & 0.279 & -0.627 & -0.186 & 0.281 & -0.662 \\
\hline Age & 0.002 & 0.014 & 0.143 & 0.003 & 0.014 & 0.214 \\
\hline No. of children & -0.057 & 0.101 & -0.564 & -0.059 & 0.102 & -0.578 \\
\hline Time pressure & & & & -0.060 & 0.066 & -0.909 \\
\hline Situational constraints & & & & -0.247 & 0.099 & $-2.495^{*}$ \\
\hline Role ambiguity & & & & 0.094 & 0.188 & 0.050 \\
\hline Hours worked & & & & -0.105 & 0.035 & $-3.000^{* * *}$ \\
\hline$-2 \times \log (\mathrm{lh})$ & \multicolumn{3}{|c|}{$1,017.593$} & \multicolumn{3}{|c|}{996.243} \\
\hline Difference of $-2 \times \log ^{a}$ & \multicolumn{3}{|c|}{1.007} & \multicolumn{3}{|c|}{$21.350^{* * * *}$} \\
\hline$d f$ & \multicolumn{3}{|c|}{3} & \multicolumn{3}{|c|}{4} \\
\hline Level 1 intercept variance (SE) & \multicolumn{3}{|c|}{$0.731(0.061)$} & \multicolumn{3}{|c|}{$0.675(0.057)$} \\
\hline Level 2 intercept variance (SE) & \multicolumn{3}{|c|}{$0.441(0.097)$} & \multicolumn{3}{|c|}{$0.463(0.098)$} \\
\hline
\end{tabular}

Note. Model 1 was compared with a null model, with intercept as the only predictor, $\gamma=0.003 ; S E=0.088 ; t=0.034$, $-2 \times \log =1,018.600$. Level 1 intercept variance $=0.731 ; S E=0.449 ;$ Level 2 intercept variance $=0.449 ; S E=0.098$. ${ }^{*} p<.05$. *** $p<.01{ }^{* * * *} p<.001$. 


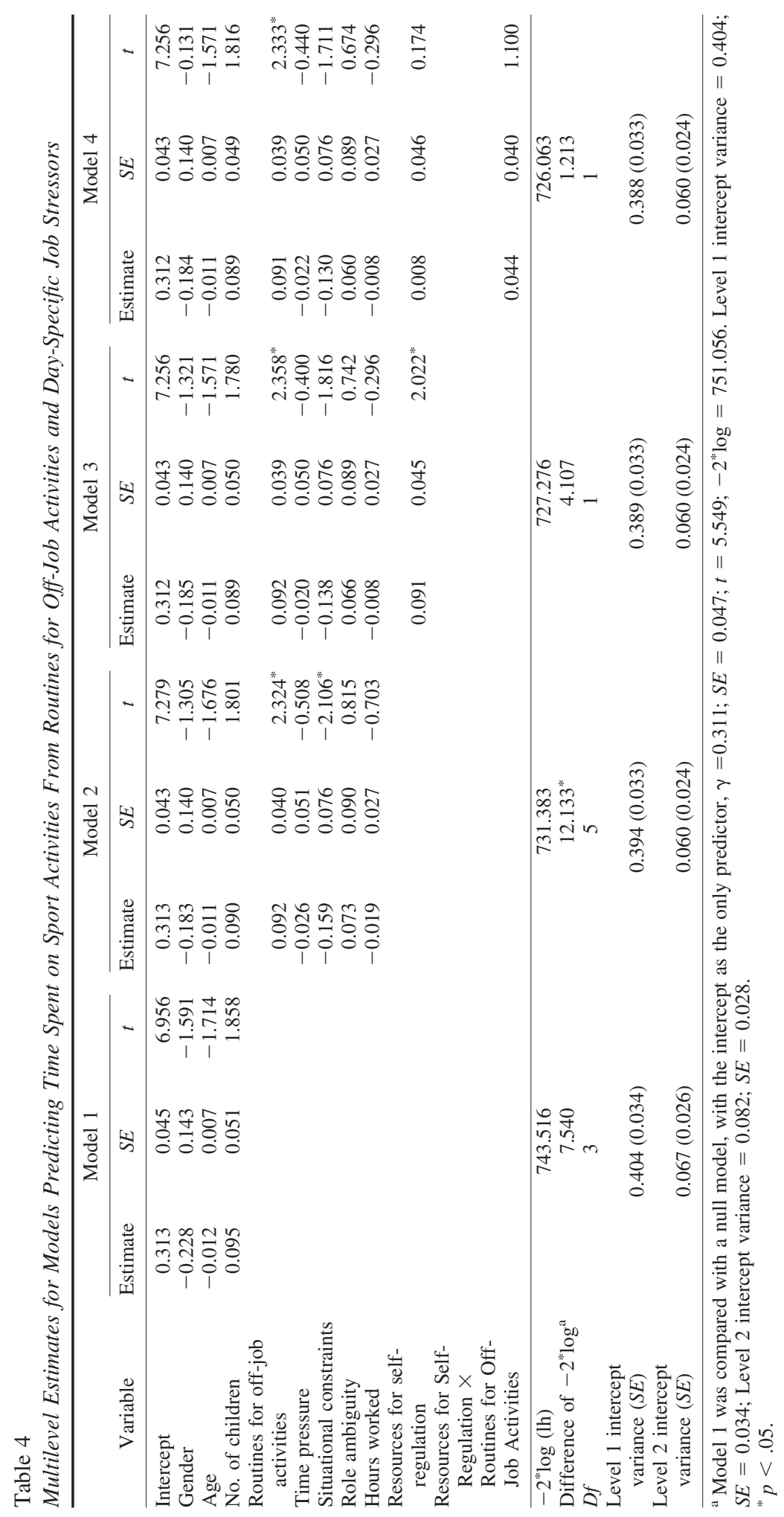




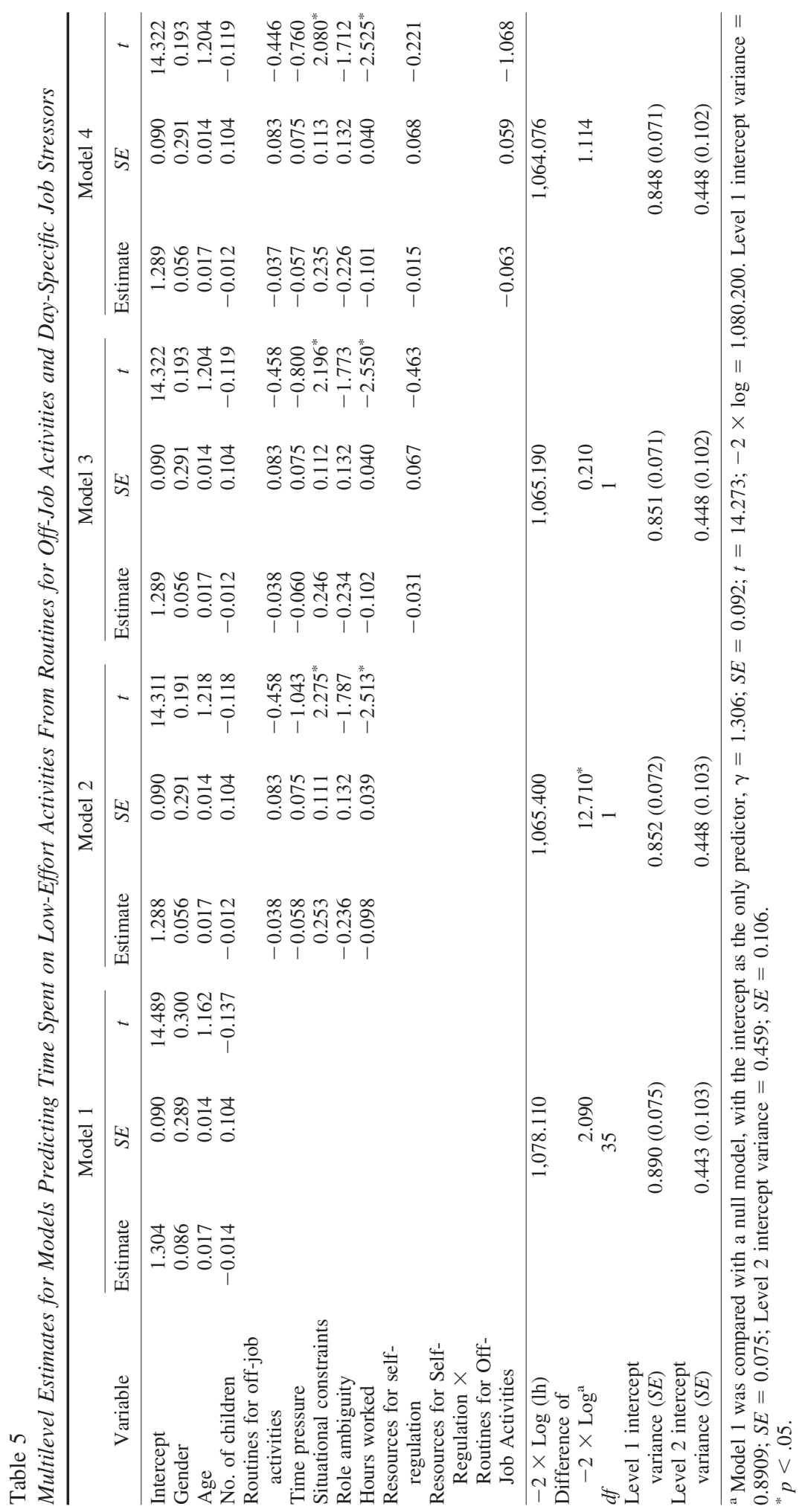


variables, did not show a better model fit than did the null model (difference of $-2^{*} \log =2.09, d f=3, n s$ ). Model 2, which included job stressors, work hours, and routines, resulted in an improved model fit (difference of $-2 * \log =12.71, d f=5, p<.01)$. Situational constraints and hours worked were significantly related to the amount of time spent on loweffort activities, with situational constraints showing a positive sign and hours worked showing a negative sign.

To test for mediation, we first examined whether the conditions specified by Baron and Kenny (1986) were met. Again, two of the conditions were met for situational constraints (cf. Tables 3 and 5). However, when entering resources for self-regulation into Model 3, the estimate of resources for self-regulation was not significant. Therefore, resources for selfregulation cannot be a mediator in the relation between job stressors and time spent on low-effort activities.

Finally, we tested Hypothesis 6B, which predicted that routines for off-job activities attenuate the relation between resources for self-regulation and time spent on low-effort activities (Model 4). Model fit did not improve (difference of $-2^{*} \log =1.114, d f=1$, $n s)$. Taken together, analyses provided partial support for Hypothesis 2B and full support for Hypothesis 4B but no support for Hypotheses $3 \mathrm{~B}$ and $6 \mathrm{~B}$.

\section{Additional Analyses: Fatigue as an Alternative Explanation}

In additional analyses, we examined whether the relation between job stressors and time spent on sport and low-effort activities can be accounted by fatigue after work. First, we tested whether job stressors (time pressure, role ambiguity, situational constraints) and hours worked predicted fatigue. Multilevel analysis showed that a model that included job stressors and hours worked had a better model fit than a model that only included demographic information (i.e., gender, age, number of children) as control variables (difference of $-2 * \log =47.594, d f=4$, $p<.001)$. Time pressure $(\gamma=0.234, S E=0.063$, $t=3.71, p<.001)$ and hours worked $(\gamma=0.135$, $S E=0.033, t=4.09, p<.001)$ were significant predictors, but situational constraints $(\gamma=0.152$, $S E=0.093, t=1.63, n s)$ and role ambiguity $(\gamma=$ $0.049, S E=0.111, t=0.44, n s)$ were not. Then, we took Model 2 displayed in Table 4 as a starting point and added fatigue (instead of resources for selfregulation) into this model. Model fit did not increase (difference of $-2 * \log =0.666, d f=1, n s$ ), and fatigue did not predict time spent on sport activities $(\gamma=-0.039, S E=0.048, t=-0.81, n s)$. The estimate of situational constraints remained significant $(\gamma=-0.154, S E=0.076, t=-2.32, p<.05)$. Similarly, we added fatigue to Model 2 (see Table 5) when predicting time spent on low-effort activities. Again, model fit did not increase (difference of $\left.-2^{*} \log =0.465, d f=1, n s\right)$, the estimate of fatigue was not significant $(\gamma=-0.048, S E=0.070, t=$ $-0.69, n s)$, and situational constraints remained a significant predictor $(\gamma=0.260, S E=0.112, t=$ $2.03, p<.05)$. Taken together, these analyses show that fatigue after work is not a mediator in the relation between situational constraints and time spent on sport and low-effort activities: Fatigue was not predicted by situational constraints, and it did not predict time spent on off-job activities.

\section{Additional Analyses: Assumed and Experienced Recovery Effects}

Our analyses have shown that participants spent less time on sport activities and more time on loweffort activities after having faced a high level of situational constraints at work. This result would be not very interesting if participants had felt that loweffort activities provide better recovery than do sport activities. Therefore, we compared the assumed and experienced recovery effects of sport and low-effort activities. As shown in Table 1, the assumed recovery effect based on questionnaire data was higher for sport activities than for low-effort activities, $t(77)=$ 2.34, $p<.05$. Similarly, experienced recovery after having performed sport activities was higher than experienced recovery after having performed loweffort activities, $t(43)=6.24, p<.001$. As it may be that sport activities do not show a high recovery effect after a highly stressful working day, we analyzed whether the experienced recovery effects of sport and low-effort activities were smaller when job stressors (e.g., time pressure, role ambiguity, situational constraints) were high. At the person level, there were no significant relations between job stressors and experienced recovery effects of sport and low-effort activities (see Table 1). At the day level, correlations between job stressors and experienced recovery effects of sport and low-effort activities were small and mostly nonsignificant (only role ambiguity was negatively related to the experienced recovery effect of low-effort activities, $r=-.12$; $n=273, p<.05)$. Taken together, these analyses 
rule out the explanation that, after a stressful day at work, people engage less in sport activities because they regard these activities as less effective with respect to recovery.

\section{Discussion}

Our study showed that after having faced a high degree of situational constraints at work, people have fewer resources available for self-regulation and spend less time on sport activities and more time on low-effort activities. Resources for self-regulation mediated the relation of situational constraints with time spent on sport activities but not the relation with low-effort activities. Long work hours were negatively related to resources for self-regulation and to time spent on low-effort activities but not to time spent on sport activities. Routines for off-job activities were positively related to the pursuit of sport activities but did not moderate the relation between job stressors and time spent on sport or low-effort activities. Fatigue after work did not predict engagement in sport or low-effort activities.

As a whole, the study findings point to a paradox. People perceive sport activities as more recovering than low-effort activities but generally spend little time on sport activities. Most important, the more situational constraints they encounter at work on a specific day, the more likely it is that they spend more time on low-effort activities and little time on sport activities. Thus, on days when it is important to engage in effective recovery activities (i.e., sport activities), people prefer activities that are suboptimal for recovery (i.e., low-effort activities).

Situational constraints, but not time pressure or role ambiguity, were related to resources for selfregulation and time spent on off-job activities. The failure to find significant relations between time pressure and role ambiguity on the one hand and resources for self-regulation and off-job activities on the other hand cannot be attributed to particularly low reliabilities of the scales or to low within-person variance of these stressors (actually, situational constraints showed the smallest within-person variation). Instead, we suggest that specific features of situational constrains referring to problems and difficulties at work are responsible for the results. In the police context, situational constraints include missing, incomplete, or outdated information; failures in communication tools; and malfunctioning of computers and other equipment. Thus, situational constraints require a particularly high degree of effort and selfregulation, for example, by requiring a person to search for missing information or find ways to circumvent breakdowns of technical equipment (Frese \& Zapf, 1994; Leitner \& Resch, 2005). As a consequence, self-regulatory resources are depleted at the end of the working day. In addition, as situational constraints refer to hassles and other negative events at work, they will result in negative affective reactions (e.g., anger; Zohar, 1999). Because most often it is not desirable to show negative affect at work, situational constraints require inhibitory processes to suppress open expressions of anger. Muraven and Baumeister (2000) have argued that particularly inhibitory processes consume self-regulatory resources. Thus, situational constraints may call for more effort investment and for more self-regulation than time pressure and role ambiguity and, therefore, may leave fewer resources for subsequent selfregulation.

Resources for self-regulation were a mediator in the relation between situational constraints and time spent on sport activities but not in the relation between situational constraints and time spent on loweffort activities. This finding suggests that situational constraints increase the tendency to spend more time on low-effort activities through other mediating mechanisms. Fatigue did not mediate the relation between situational constraints and sport activities. Thus, the lack of self-regulatory resources (i.e., lack of energy but not the fact of being tired) seems to be important for not initiating sport activities.

Hours worked were negatively related to the amount of time spent on low-effort activities but not to the amount of sport activities. It seems that engagement in sport is not hampered by long working hours and that time scarcity is not an appropriate explanation for a low amount of time spent on sport activities. An alternative interpretation for the finding that hours worked were not related to time spent on sport activities may be that people return from work relatively early when they intend to engage in sports during the evening. However, particularly in times of emergencies, police employees may have only limited control over the number of hours they work on a specific day. Therefore, for these employees it is not very likely that the dissociation between long working hours and time spent on sport activities is due to the deliberate anticipation of sport activities.

Routines for off-job activities were positively related to time spent on sport activities. This finding suggests that routines help in initiating and persisting in sport. However, some sport activities also require a certain degree of routines. For example, in team sports such as soccer or volleyball, it is useful to 
establish routines for gathering with teammates. Thus, routines for off-job activities may not only facilitate sport activities but may also be a necessity when performing a specific type of sport activity. They also may be beneficial for other activities in people's lives.

This study did not show any interaction effect between resources for self-regulation and routines for off-job activities on the amount of time spent on sport and low-effort activities. This result may imply that routines for off-job activities are not particularly helpful when resources tend to be depleted, although they are generally associated with time spent on sport. It has to be noted that we assessed rather general routines referring to all possible types of off-job activities. It may be that more specific routines are needed to overcome self-regulatory deficits. Routines that specify when and where to pursue a specific activity may help to weaken the negative relation between depleted resources and engagement in sport activities.

Our findings point in a direction similar to that of other studies on the relation between job stressors and experiences during off-job time. These studies have shown that job stressors, particularly time pressure and long working hours, make it difficult to unwind and to psychologically detach from work during off-job time (Grebner, Semmer, \& Elfering, 2005; Sonnentag \& Fritz, 2007). Although a final conclusion seems to be premature, the pattern of findings suggests that different stressors are not uniformly related to experiences and behavior off the job: Stressors related to overload (i.e., time pressure, overtime) tend to impede unwinding and psychological detachment after work, whereas stressors related to the depletion of self-regulatory resources (i.e., situational constraints) may make the initiation of effortful off-job activities more difficult.

Although it may be that the effect of not engaging in sport activities after a stressful day is inconsequential on overall, long-term health if people engage in sport activities on other days, it must noted that sports are potent recovery activities because physical activities can enhance mood within 10 to $20 \mathrm{~min}$ (Hansen, Stevens, \& Coast, 2001), an effect that would be particularly beneficial after a stressful day. Furthermore, not engaging in sport activities after a stressful day will become problematic if the frequency of stressful days increases and when doing no sport becomes the dominant pattern of off-job behavior.

\section{Limitations}

Our study has some limitations. First, the study relied on self-report data. Therefore, common method variance may be a problem (Podsakoff, MacKenzie, Lee, \& Podsakoff, 2003). However, although it would have been preferable to have coworkers or spouses to assess job stressors and off-job time activities, respectively, we tried to minimize common method bias by temporally and methodologically separating the measurement of our study variables. For example, we assessed day-specific job stressors with Likert-type items and time spent on activities with open-ended questions. Such a procedure helps to reduce common method bias (Podsakoff et al., 2003).

Second, our study was based on a sample of police employees. Police jobs often are associated with physical demands, and police employees may be more physically fit than other groups of employees. Therefore, it may not be surprising that participants assumed and perceived sport activities as more recovering than low-effort activities. This specific sample may question the generalizability of our findings. However, we argue that this sample of police employees did not work for but against the hypotheses. Our study demonstrated that employees from an occupational group that may be inclined to pursue sport activities spent less time on them after having faced situational constraints at work. One may speculate that employees from other occupational groups who are not as used to pursuing sports may find it even more difficult to engage in sport activities after a stressful day. Without doubt, studies with employees from other occupational groups are needed.

\section{Implications for Future Research and Practice}

We assessed resources for self-regulation by asking study participants about their level of energy after work. As self-reports provide only partial insight into self-regulatory processes, future studies should go beyond the self-report measures and examine the exhaustion of self-regulatory resources after stressful working days more directly. For example, employees could be invited to come to a laboratory after work and complete tasks suitable for assessing selfregulatory strength, such as resisting temptation or persistence in the face of unsolvable tasks (Baumeister et al., 1998). Use of measures that refer to the physical basis of self-regulation may be another option (Gaillot et al., 2007). 
It would be an interesting and practically relevant avenue for future research to examine factors that attenuate the negative relation between job stressors and sport activities; that is, to identify strategies that help people to pursue sport activities after stressful working days. Here, various approaches seem to be promising. First, Muraven, Baumeister, and Tice (1999) proposed that self-regulatory strength benefits from self-regulatory practice and exercise. For our research context, this suggestion implies that people should be trained how to start effortful off-job behavior when self-regulatory resources are already depleted. Second, implementation intentions may help to initiate sport activities also when selfregulatory resources tend to be depleted. An implementation intention is a self-regulatory strategy that links a specific anticipated future situation to a specific goal-directed behavior (Gollwitzer, 1999). On the basis of findings from other domains, it can be expected that implementation intentions are much more successful in supporting a person in starting sport activities than are more general goal intentions, which have been shown to be relatively ineffective, particularly under stressful conditions (Payne et al., 2002; but cf. Budden \& Sagarin, 2007). Moreover, researchers in future studies may want to examine personality and other individual difference variables as moderators in the relationship between depletion of self-regulatory resources and pursuit of off-job time activities. For example, it may be that individual high on trait self-control engage in sport activities also when their self-regulatory resources tend to be depleted. Individuals high on extraversion may pursue other low-effort activities (e.g., informally socializing with friends) than do individuals high on introversion (e.g., staying at home and reading a magazine).

Future research may examine not only job stressors but also other factors that reduce resources for self-regulation. For example, long and stressful commutes or responsibilities in the home (e.g., caring for aging parents) may severely limit resources available for self-regulation. In this study, we measured overall time devoted on the specific activity categories during a day. In future studies, researchers may want to differentiate between various types of sport activities. In addition, it may be fruitful to assess more detailed patterns of time use that include information about sequences and durations of smaller units of activities. Such a procedure may allow a more fine-grained analysis of transition frequencies from one activity to another. By doing so, specific configurations of pre- ceding activities that help versus hinder engagement in sport activities can be identified.

Before we know more about the effects of these approaches, people may be advised to engage in sport activities at times when resources are not (yet) depleted. For example, instead of postponing sports for the evening, they may want to go for a run in the morning or during lunch break. As even a small amount of time spent on exercise and sport activities improves mood (Hansen et al., 2001), work-related affect and behavior may quickly benefit from sport pursued earlier during the day. An alternative suggestion is to make at least the initiation of sport activities less resource dependent, for example, by packing the sport bag in the morning when one still has the necessary willpower.

Moreover, individuals may schedule a short time for relaxation after work for replenishing their resources so that enough resources will be available later for initiating more effortful off-job activities. However, for many people, it will be difficult to spend quiet time on relaxation after work because family responsibilities may require immediate attention.

\section{Conclusion}

Taken together, our study has shown that job stressors are related to off-job activities pursued after work. The limited-resources model of self-regulation offers an explanation for the process by which the "long arm of the job" (Meissner, 1971) may operate within individuals' daily lives. Moreover, our study adds to previous research on the consequences of job stressors. Job stressors not only directly affect health and well-being but also make the pursuit of healthpromoting behaviors more difficult.

\section{References}

Aarts, H., \& Dijksterhuis, A. (2000). Habits as knowledge structures: Automaticity in goal-directed behavior. Journal of Personality and Social Psychology, 78, 52-63.

Baron, R. M., \& Kenny, D. A. (1986). The moderatormediator variable distinction in social psychological research: Conceptual, strategic and statistical considerations. Journal of Personality and Social Psychology, 51, 1173-1182.

Baumeister, R. F., Bratslavsky, E., Muraven, M., \& Tice, D. M. (1998). Ego depletion: Is the active self a limited resource? Journal of Personality and Social Psychology, 74, 1252-1265.

Bolger, N., Davis, A., \& Rafaeli, E. (2003). Diary methods: Capturing life as it is lived. Annual Review of Psychology, 54, 579-616. 
Bryk, A. S., \& Raudenbush, S. W. (1992). Hierarchical linear models: Application and data analysis methods. Newbury Park, CA: Sage.

Budden, J. S., \& Sagarin, B. J. (2007). Implementation intentions, occupational stress, and the exercise intention-behavior relationship. Journal of Occupational Health Psychology, 12, 391-401.

Craig, A., \& Cooper, R. E. (1992). Symptoms of acute and chronic fatigue. In A. P. Smith \& D. M. Jones (Eds.), Handbook of human performance (Vol. 3, pp. 289-339). London: Academic Press.

De Croon, E. M., Sluiter, J. K., Blonk, R. W. B., Broersen, J. P. J., \& Frings-Dresen, M. H. W. (2004). Stressful work, psychological job strain, and turnover: A 2-year prospective cohort study of truck drivers. Journal of Applied Psychology, 89, 442-454.

Demerouti, E., Bakker, A. B., \& Bulters, A. J. (2004). The loss spiral of work pressure, work-home interference and exhaustion: Reciprocal relations in a three-way study. Journal of Vocational Behavior, 64, 131-149.

Dubbert, P. M. (2002). Physical activity and exercise: Recent advances and current challenges. Journal of Consulting and Clinical Psychology, 70, 526-536.

Elfering, A., Grebner, S., Semmer, N. K., KaiserFreiburghaus, D., Lauper-del Ponte, S., \& Witschi, I. (2005). Chronic job stressors and job control: Effects on event-related coping success and well-being. Journal of Occupational and Organizational Psychology, 78, 237252.

Frese, M., \& Zapf, D. (1994). Action as the core of work psychology: A German approach. In H. C. Triandis, M. D. Dunnette, \& L. M. Hough (Eds.), Handbook of industrial and organizational psychology, Vol. 4 (2nd ed., pp. 271-340). Palo Alto, CA: Consulting Psychologists Press.

Fuller, J. A., Stanton, J. M., Fisher, G. G., Spitzmüller, C., Russell, S. S., \& Smith, P. C. (2003). A lengthy look at the daily grind: Time series analyses of events, mood, stress, and satisfaction. Journal of Applied Psychology, 88, 1019-1033.

Gaillot, M. T., \& Baumeister, R. F. (2007). The physiology of willpower: Linking blood glucose to self-control. Personality and Social Psychology Review, 11, 303-327.

Gaillot, M. T., Baumeister, R. F., DeWall, C. N., Maner, J. K., Plant, E. A., Tice, D. M., et al. (2007). Self-control relies on glucose as a limited energy source: Willpower is more than a metaphor. Journal of Personality and Social Psychology, 92, 325-336.

Garst, H., Frese, M., \& Molenaar, P. C. M. (2000). The temporal factor of change in stressor-strain relationships: A growth curve model on a longitudinal study in East Germany. Journal of Applied Psychology, 85, 417-438.

Gollwitzer, P. M. (1999). Implementation intentions: Strong effects of simple plans. American Psychologist, 54, 493503.

Grebner, S., Semmer, N. K., \& Elfering, A. (2005). Working conditions and three types of well-being: A longitudinal study with self-report and rating data. Journal of Occupational Health Psychology, 10, 31-43.

Hansen, C. J., Stevens, L. C., \& Coast, J. R. (2001). Exercise duration and mood state: How much is enough to feel better? Health Psychology, 20, 267-275.

Hellerstadt, W. L., \& Jeffery, R. W. (1997). The association of job strain and health behaviours in men and women. International Journal of Epidemiology, 26, 575-583.

Hockey, G. R. J. (1997). Compensatory control in the regulation of human performance under stress and high workload: A cognitive-energetical framework. Biological Psychology, 45, 73-93.

Ilies, R., Schwind, K. M., \& Heller, D. (2007). Employee well-being: A multilevel model linking work and nonwork domains. European Journal of Work and Organizational Psychology, 16, 326-341.

Ilies, R., Schwind, K. M., Wagner, D. T., Johnson, M. D., DeRue, D. S., \& Ilgen, D. R. (2007). When can employees have a family life? The effects of daily workload and affect on work-family conflict and social behavior at work. Journal of Applied Psychology, 92, 1368-1379.

Jannson, M., \& Linton, S. J. (2006). Psychosocial work stressors in the development and maintenance of insomnia: A prospective study. Journal of Occupational Health Psychology, 11, 241-248.

Jex, S. M. (1998). Stress and job performance: Theory, research, and implications for managerial practice. Thousand Oaks, CA: Sage.

Jones, F., O'Connor, D. B., Conner, M., McMillan, B., \& Ferguson, E. (2007). Impact of daily mood, work hours, and iso-strain variables on self-reported health behaviors. Journal of Applied Psychology, 92, 1731-1740.

Kahn, R. L., \& Byosiere, P. (1992). Stress in organizations. In M. D. Dunnette \& L. M. Hough (Eds.), Handbook of industrial and organizational psychology, Vol. 3 (2nd ed., pp. 571-650). Palo Alto, CA: Consulting Psychologists Press.

Kop, N., Euwema, M., \& Schaufeli, W. B. (1999). Burnout, job stress and violent behavior among Dutch police officers. Work and Stress, 13, 326-340.

Krull, J. L., \& MacKinnon, D. P. (2001). Multilevel modeling of individual and group level mediated effects. Multivariate Behavioral Research, 36, 249-277.

Larsen, R. J., \& Prizmic, Z. (2004). Affect regulation. In R. F. Baumeister \& K. D. Vohs (Eds.), Handbook of self-regulation: Research, theory, and applications (pp. 40-61). New York: Guilford Press.

Leitner, K., \& Resch, M. G. (2005). Do the effects of job stressors on health persist over time? A longitudinal study with observational stressor measures. Journal of Occupational Health Psychology, 10, 18-30.

MacKinnon, D. P., \& Dwyer, J. H. (1993). Estimating mediated effects in prevention studies. Evaluation Review, 17, 144-158.

Major, V. S., Klein, K. J., \& Ehrhart, M. G. (2002). Work time, work interference with family, and psychological distress. Journal of Applied Psychology, 87, 427-436.

McNair, D. M., Lorr, M., \& Droppelman, L. F. (1971). EITS manual for the Profile of Mood States. San Diego, CA: EdITS.

Meijman, T. F., \& Mulder, G. (1998). Psychological aspects of workload. In P. J. D. Drenth \& H. Thierry \& C. J. d. Wolff (Eds.), Handbook of work and organizational psychology, Vol. 2: Work psychology (pp. 5-33). Hove, England: Psychology Press.

Meissner, M. (1971). The long arm of the job: A study of work and leisure. Industrial Relations, 10, 239-260.

Muraven, M., \& Baumeister, R. F. (2000). Self-regulation and depletion of limited resources: Does self-control 
resemble a muscle. Psychological Bulletin, 126, 247259.

Muraven, M., Baumeister, R. F., \& Tice, D. M. (1999). Longitudinal improvement of self-regulation through practice: Building self-control through repeated exercise. Journal of Social Psychology, 139, 446-457.

Ng, D. M., \& Jeffery, R. W. (2003). Relationships between perceived stress and health behaviors in a sample of working adults. Health Psychology, 22, 638-642.

Nomaguchi, K. M., \& Bianchi, S. M. (2004). Exercise time: Gender differences in the effects of marriage, parenthood, and employment. Journal of Marriage and the Family, 66, 413-430.

Oaten, M., \& Cheng, K. (2005). Academic examination stress impairs self-control. Journal of Social and Clinical Psychology, 24, 254-279.

Ouellette, J. A., \& Wood, W. (1998). Habit and intention in everyday life: The multiple processes by which past behavior predicts future behavior. Psychological Bulletin, 124, 54-74.

Payne, N., Jones, F., \& Harris, P. (2002). The impact of working life on health behavior: The effect of job strain on the cognitive predictors of exercise. Journal of Occupational Health Psychology, 7, 342-353.

Peters, L. H., Chassie, M. B., Lindholm, H. R., O'Connor, E. J., \& Kline, C. R. (1982). The joint influence of situational constraints and goal setting on performance and affective outcomes. Journal of Management, 8, 7-20.

Petruzzello, S. J., Landers, D. M., Hatfield, B. D., Kubitz, K. A., \& Salazar, W. (1991). A meta-analysis on the anxiety-reducing effects of acute and chronic exercise. Sports Medicine, 11, 143-182.

Podsakoff, P. M., MacKenzie, S. B., Lee, J.-Y., \& Podsakoff, N. P. (2003). Common method biases in behavioral research: A critical review of the literature and recommended remedies. Journal of Applied Psychology, 88, 879-903.

Puetz, T. W., O'Connor, P. J., \& Dishman, R. K. (2006). Effects of chronic exercise on feelings of energy and fatigue: A quantitative synthesis. Psychological Bulletin, 132, 866-876.

Roberts, N. A., \& Levenson, R. W. (2001). The remains of the workday: Impact of job stress and exhaustion on marital interaction in police couples. Journal of Marriage and the Family, 63, 1052-1067.

Schmeichel, B. J., \& Baumeister, R. F. (2004). Selfregulatory strength. In R. F. Baumeister \& K. D. Vohs (Eds.), Handbook of self-regulation: Research, theory, and applications (pp. 84-98). New York: Guilford Press.

Semmer, N. (1984). Streßbezogene Tätigkeitsanalyse [Stress-oriented analysis task-analysis]. Weinheim, Germany: Beltz.

Semmer, N., Zapf, D., \& Dunckel, H. (1999). Instrument zur Streßbezogenen Tätigkeitsanalyse [Instrument for stress-oriented job analysis] (ISTA). In H. Dunckel (Ed.), Handbuch psychologischer Arbeitsanalyseverfahren [Handbook of instruments for psychological work anal- ysis] (pp. 179-204). Zürich, Switzerland: Vdf Hochschulverlag an der ETH.

Sonnentag, S. (2001). Work, recovery activities, and individual well-being: A diary study. Journal of Ocсupational Health Psychology, 6, 196-210.

Sonnentag, S., \& Fritz, C. (2007). The Recovery Experience Questionnaire: Development and validation of a measure assessing recuperation and unwinding at work. Journal of Occupational Health Psychology, 12, 204-221.

Sonnentag, S., \& Natter, E. (2004). Flight attendants' daily recovery from work: Is there no place like home? International Journal of Stress Management, 11, 366-391.

Sonnentag, S., \& Zijlstra, F. R. H. (2006). Job characteristics and off-job time activities as predictors for need for recovery, well-being, and fatigue. Journal of Applied Psychology, 91, 330-350.

Steptoe, A., Lipsey, Z., \& Wardle, J. (1998). Stress, hassles and variations in alcohol consumption, food choice and physical exercise: A diary study. British Journal of Health Psychology, 3, 51-63.

Stetson, B. A., Rahn, J. M., Dubbert, P. M., Wilner, B. I., \& Mercury, M. G. (1997). Prospective evaluation of the effects of stress on exercise adherence in communityresiding women. Health Psychology, 16, 515-520.

Tenenbaum, G., \& Hutchinson, J. (2007). A socialcognitive perspective of perceived and sustained effort. In G. Tenenbaum \& R. C. Eklund (Eds.), Handbook of sport psychology (3rd ed., pp. 560-577). Hoboken, NJ: Wiley.

Thayer, R. E. (1987). Energy, tiredness, and tension effects of a sugar snack versus moderate exercise. Journal of Personality and Social Psychology, 52, 119-125.

Thayer, R. E., Newman, J. R., \& McClain, T. M. (1994). Self-regulation of mood: Strategies for changing a bad mood, raising energy, and reducing tension. Journal of Personality and Social Psychology, 67, 910-925.

van Hooff, M. L. M., Geurts, S. A. E., Kompier, M. A. J., \& Taris, T. W. (2006). Work-home interference: How does it manifest itself from day to day? Work and Stress, 20, 145-162.

Wood, W., Quinn, J. M., \& Kashy, D. A. (2002). Habits in everyday life: Thought, emotion, and action. Journal of Personality and Social Psychology, 83, 1281-1297.

Zapf, D. (1993). Stress-oriented analysis of computerized office work. European Work and Organizational Psychologist, 3, 85-100.

Zohar, D. (1999). When things go wrong: The effect of daily work hassles on effort, exertion and negative mood. Journal of Occupational and Organizational Psychology, 72, 265-283.

Zohar, D., Tzischinski, O., \& Epstein, R. (2003). Effects of energy availability on immediate and delayed emotional reactions to work events. Journal of Applied Psychology, 88, 1082-1093. 